\title{
Mitochondria: Key Organelles Accelerating Cell Wall Material Accumulation in Juice Sacs of Pummelo (Citrus grandis L. Osbeck) Fruits during Postharvest Storage
}

\author{
Yanqing Lu, Yanjin Lin, and Xinkun Lu $\mathbb{D}$ \\ Institute of Pomology, Fujian Academy of Agricultural Sciences, Fuzhou 350000, China \\ Correspondence should be addressed to Xinkun Lu; gsskg@126.com
}

Received 3 June 2021; Accepted 9 August 2021; Published 3 September 2021

Academic Editor: Daniel Cozzolino

Copyright (c) 2021 Yanqing Lu et al. This is an open access article distributed under the Creative Commons Attribution License, which permits unrestricted use, distribution, and reproduction in any medium, provided the original work is properly cited.

\begin{abstract}
Granulation is a physiological disorder of juice sacs in citrus fruits, which develops through secondary cell wall formation. However, the synergistic changes in the cytoplasm of juice sac cells remain largely unknown. This study investigated the dynamic ultrastructure of juice sacs of "Guanxi" pummelo fruits by transmission electron microscopy and determined their cell wall material, soluble sugar, and organic acid contents. The results showed that lignin and hemicellulose are accumulated in juice sacs isolated from dorsal vascular bundles, while lignin and cellulose contribute to the granulation of juice sacs isolated from septal vascular bundles. The significant differences in lignin, cellulose, and hemicellulose contents between the two types of juice sacs began to be observed at 30 days of storage. Fructose levels were elevated in juice sacs isolated from the dorsal vascular bundles from 10 to 60 days. Sucrose contents significantly decreased in juice sacs isolated from the septal vascular bundles from 30 to 60 days. Meanwhile glucose, citric acid, and malic acid contents exhibited no apparent changes in both types of juice sacs. Based on the comprehensive analysis of the ultrastructure of both types of juice sacs, it was clearly found that plasma membrane ruptures induce cell wall material synthesis in intracellular spaces; however, cell wall substance contents did not significantly increase until the number of mitochondria sharply increased. In particular, sucrose contents began to decrease significantly just after the mitochondria amount largely increased in juice sacs isolated from the septal vascular bundles, indicating that mitochondria play a key role in regulating carbon source sugar partitioning for cell wall component synthesis.
\end{abstract}

\section{Introduction}

Citrus is an important fruit tree crop around the world. Juice sac granulation of citrus fruits is a severe physiological disorder during the late growing season and postharvest storage of citrus fruits. This disorder is characterized by an increase in firmness and a decrease in the flavour quality of juice sacs. A high rate of juice sac granulation leads to severe decline not only in fruit quality but also in the economic effectiveness of the citrus industry. Granulation rates of citrus fruits vary widely. For lime, orange, and mandarin, they range from $10 \%$ to over $80 \%[1,2]$.

Studies have demonstrated that a secondary cell wall is formed in juice sacs during citrus fruit granulation $[3,4]$. Also, sugar contents decrease in granulated juice sacs $[5,6]$. Moreover, the abundance of organic acids varies strongly.
Citric acid and isocitric acid contents decrease but malic acid levels increase in granulated juice sacs of "Guanxi" pummelo fruits [7].

Transcriptome data of granulating juice sacs of ponkan fruits provided evidence explaining the changes in carbohydrate contents: the expression levels of genes encoding enzymes involved in the sugar and citric acid degradation pathways significantly increased, while transcript levels of enzymes that participate in the synthesis pathways of sugar and citric acid greatly decreased [8]. Phenols are precursors of lignin [9], which decrease in juice sacs during granulation development of citrus fruits $[3,10]$. Lignin accumulation is positively associated with the degree of juice sac granulation [11]. Besides, cellulose and hemicellulose contents also exhibit increasing trends during granulation [12]. Phenylalanine ammonia lyase (PAL) and cinnamyl alcohol 
dehydrogenase (CAD) are enzymes involved in the lignin biosynthesis pathway. Increases in the activities and transcript levels of the two enzymes improve lignin accumulation [13-15]. Reports demonstrated that elevated PAL and CAD activities were accompanied by an increase in the degree of granulation of pummelo fruits [11]. In addition, activities of enzymes that participate in the cell wall degradation pathway declined in granulated juice sacs of pummelo fruits, including pectin methylesterase, polygalacturonase, and cellulase [12]. These findings indicate that sugar and organic acid degradation may be connected with cell wall material synthesis in granulated juice sacs.

It has been demonstrated that various critical factors may be involved in the regulation of juice sac granulation: hydrogen peroxide $\left(\mathrm{H}_{2} \mathrm{O}_{2}\right)$ and abscisic acid are positively associated with granulation of pummelo fruits, while auxin is negatively linked [16-18]. Three MYB transcription factors (CsMYB330, CsMYB308, and CsMYB85) regulate the expression level of Cs4CL1, a gene encoding for a 4-coumaric acid coenzyme A ligase. CsMYB330 and CsMYB308 can recognize and bind $\mathrm{AC}$ elements in the Cs4CL1 promoter and act as a transcription activator and a transcription suppressor, respectively. Additionally, CsMYB85 binds the CsMYB330 promoter and thereby regulates CsMYB330 expression levels. Also, CsMYB85 overexpression leads to higher Cs4CL1 expression levels and higher lignin accumulation in juice sacs of sweet orange $[19,20]$. These findings are beneficial for explaining the juice sac granulation mechanism; however, the organization of these factors in signaling networks is still poorly understood.

Most metabolic pathways are closely associated with specific organelles in plant cells. For instance, proteins involved in the tricarboxylic acid cycle, oxidative phosphorylation, and biosynthesis of secondary metabolites can be isolated from mitochondria in the pulp of ripening citrus fruits from satsuma mandarin, ponkan mandarin, sweet orange, and pummelo [21]. Also, a high concentration of cinnamate-4-hydroxylase (an enzyme of lignin synthesis) was found in Golgi bodies in differentiating hypocotyls of French bean (Phaseolus vulgaris L.) [22], and cellulose synthases were shown to be anchored on the plasma membrane in tobacco (Nicotiana tabacum L.) plants [23]. UDP-xylose synthase, an enzyme that catalyzes the conversion of UDP-glucuronic acid to UDP-xylose, is localized in the cytoplasm and at the Golgi apparatus in different cell types of Arabidopsis thaliana [24]. Before UDP-xylose synthase complexes are accumulated at the Golgi apparatus, their subunits are assembled at particular areas of the endoplasmic reticulum in etiolated wheat (Triticum aestivum) seedlings [25]. Besides, plasma membrane and mitochondria are two important sites for ROS generation [26, 27]. Studying this targeting of sugar metabolism components, cell wall substances, and $\mathrm{H}_{2} \mathrm{O}_{2}$ specific organelles or cell structures may provide further evidence to reveal the mechanism of citrus fruit granulation.

A previous report showed that the middle and stylar-end sections of the fruit segment are most sensitive to granulation in "Magallanes" pummelo [Citrus maxima (Burm. ex Rumph.) Merr.] [28]. In this study, we combined this information with our previous investigation of the granulation sequences of juice sacs of "Guanxi" pummel fruit. We classified juice sacs into juice sacs isolated from the dorsal vascular bundles (light granulation degree) and juice sacs isolated from the septal vascular bundles (heavy granulation degree). Based on the classification of juice sacs, the aim of this study is to reveal the important connection between ultrastructure dynamics and carbohydrate fluctuation in juice sacs of "Guanxi" pummel fruits during postharvest storage at room temperature.

\section{Materials and Methods}

2.1. Fruit Samples. We harvested 180 ripe fruits from ten "Guanxi" pummelo (Citrus grandis L. Osbeck) trees (15year-old) from a commercial orchard located in Zhangzhou City, China, on October 30, 2016. Eighteen medium-sized fruits were selected from the outside canopy (fruits grown under similar light and air conditions) of each tree. Fruits were wrapped with polyethylene to prevent water loss, divided into three biological replicates, and stored for 60 days at room temperature.

Three fruits were randomly selected from each biological replicate at $0,10,20,30,40,50$, and 60 days. Juice sacs isolated from the dorsal vascular bundles (dorsal juice sacs) and juice sacs isolated from the septal vascular bundles (septal juice sacs) were collected separately (Figure 1). Juice sac samples collected from each biological replicate were mixed and stored at $-80^{\circ} \mathrm{C}$ for the determination of cell wall materials, soluble sugar, and organic acid contents. Additionally, two types of flesh juice sacs were separately isolated from fruits stored for $0,10,20,40$, and 60 days. Flesh juice sacs were selected from one fruit that perfectly represented the granulation degree of fruits from three biological replicates at each stage. Approximately $2 \mathrm{~mm}$ long sections were dissected from juice sacs isolated from the dorsal or the septal vascular bundles and immediately fixed in 3.5\% glutaraldehyde in $0.2 \%$ phosphate buffer ( $\mathrm{pH} 7.2$ ) for two days at $4^{\circ} \mathrm{C}$.

2.2. Transmission Electron Microscopy (TEM). The fixed samples were rinsed with $0.2 \%$ phosphate buffer three times for $15 \mathrm{~min}$ each. Samples were then postfixed with a solution containing $1 \%$ osmic acid and $1.5 \%$ potassium ferrocyanide for $1.5 \mathrm{~h}$ at $4^{\circ} \mathrm{C}$. Following the postfixation, samples were again rinsed with $0.2 \%$ phosphate buffer five times for $15 \mathrm{~min}$ each. The rinsed samples were dehydrated in a graded series of ethanol and acetone: 50\% ethanol for $15 \mathrm{~min}, 70 \%$ ethanol overnight, $90 \%$ ethanol for $15 \mathrm{~min}$, a mixed solution of $90 \%$ ethanol and acetone (v/v, 1:1) for $15 \mathrm{~min}, 90 \%$ acetone for $15 \mathrm{mins}$, and anhydrous acetone for $15 \mathrm{~min}$. Dehydrated samples were infiltrated in a mixture of anhydrous acetone and epoxy resin $618(\mathrm{v} / \mathrm{v}, 1: 1)$ for $1.5 \mathrm{~h}$ and in pure epoxy resin 618 for $3 \mathrm{~h}$ at $35^{\circ} \mathrm{C}$. The samples were embedded in pure epoxy resin 618 and allowed to polymerize at $35^{\circ} \mathrm{C}$ for $12 \mathrm{~h}$, at $45^{\circ} \mathrm{C}$ for $12 \mathrm{~h}$, and at $60^{\circ} \mathrm{C}$ for $2-3 \mathrm{~h}$. The embedded tissues were cut into ultrathin sections $(90 \mathrm{~nm})$ with a glass knife on an ultramicrotome (Leica EM 


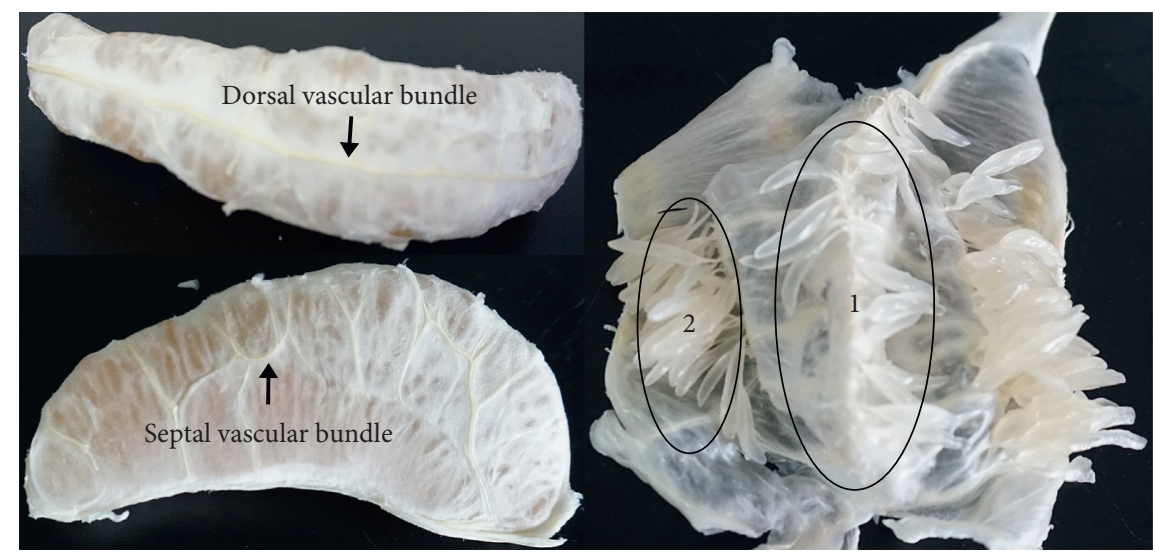

Figure 1: Illustration of two types of juice sacs. The region marked by 1 indicates dorsal juice sacs and the region marked by 2 indicates septal juice sacs.

UC7, Wetzlar, Germany) and stained with $2 \%$ uranyl acetate for $20 \mathrm{~min}$, followed by lead citrate for $3 \mathrm{~min}$. Sections were investigated using a transmission electron microscope (Hitachi, HT7700, Tokyo, Japan) at $80 \mathrm{kV}$.

2.3. Lignin Determination. The detection of lignin was carried out according to the method described by Bomal et al. [29] with some modifications. Frozen juice sacs were ground in liquid nitrogen, and $1.5 \mathrm{~g}$ powder was placed in a $10 \mathrm{~mL}$ tube and extracted with $6 \mathrm{~mL} 80 \%$ ethanol at $80^{\circ} \mathrm{C}$ for $30 \mathrm{~min}$ to remove sugar, acid, and pigment and then centrifuged at $15,000 \mathrm{~g}$ for $10 \mathrm{~min}$ at $4^{\circ} \mathrm{C}$. The residues were suspended in $80 \%$ ethanol, and the extraction was repeated twice. The pellet was resuspended with $6 \mathrm{~mL} 80 \%$ methanol and kept at room temperature for $30 \mathrm{~min}$, followed by centrifugation at $15,000 \mathrm{~g}$ for $10 \mathrm{~min}$ at $4^{\circ} \mathrm{C}$. The supernatant was removed, and the residues were extracted with methanol twice. Next, the pellet was dissolved in $6 \mathrm{~mL} \mathrm{n}$-hexane and kept at room temperature for $30 \mathrm{~min}$ to further remove pigment and lipid. This extraction was repeated twice. After centrifuging at $15,000 \mathrm{~g}$ for $10 \mathrm{~min}$ at $4^{\circ} \mathrm{C}$, the final pellet was dried in oven at $80^{\circ} \mathrm{C}$.

$10 \mathrm{mg}$ of the final pellet was transferred into $5 \mathrm{~mL}$ glass tube, and $1 \mathrm{~mL} 25 \%$ acetyl bromide (dissolved in glacial acetic acid) was added. The sample solution was incubated at $50^{\circ} \mathrm{C}$ for $2 \mathrm{~h} .2 \mathrm{~mL}$ of $2 \mathrm{M} \mathrm{NaOH}$ solution and $5 \mathrm{~mL}$ glacial acetic acid was added to a $25 \mathrm{~mL}$ volumetric flask. The extracted solution was added, followed by $0.35 \mathrm{~mL} 0.5 \mathrm{M}$ hydroxylamine. Finally, the mixed solution was filled up to $25 \mathrm{~mL}$ with glacial acetyl acid. The absorbance of lignin was detected using an ultraviolet spectrophotometer at $280 \mathrm{~nm}$.

2.4. Cellulose and Hemicellulose Determination. The analyses of cellulose and hemicellulose content were performed using the method described by Ookawa et al. [30] with slight modifications. Flesh samples were weighed and recorded as W0. Removal of sugar, acid, pigment, and lipid from the sample was performed as described for the lignin determination. The dried pellet was weighed and recorded as $W 1$. $20 \mathrm{mg}$ of the dried pellet was digested in $1 \mathrm{~mL} 15 \mathrm{U} \cdot \mathrm{ml}^{-1} \mathrm{a}-$ amylase solution at $85^{\circ} \mathrm{C}$ for $30 \mathrm{~min}$ to remove starch, followed by centrifugation at $15,000 \mathrm{~g}$ for $10 \mathrm{~min}$ at $4^{\circ} \mathrm{C}$. The supernatant was discarded, and the residue was dried at $80^{\circ} \mathrm{C}$. The dry pellet was mixed with $650 \mu \mathrm{L}$ ultrapure water, $6 \mathrm{mg} \mathrm{ClNaO}$, and $5 \mu \mathrm{L}$ glacial acetyl acid and subsequently placed in water for $1 \mathrm{~h}$ at $80^{\circ} \mathrm{C}$ to remove lignin. These steps were repeated twice. Next, the pellet was washed with ultrapure water and dried at $80^{\circ} \mathrm{C}$. The delignified pellet was resuspended with $1 \mathrm{~mL}$ neutral detergent solution $(18 \mathrm{mM}$ sodium tetraborate decahydrate, $66 \mathrm{mM}$ ethylenediaminetetraacetic acid, $10.4 \mathrm{mM}$ sodium dodecyl sulfate, $32 \mathrm{mM}$ dibasic sodium phosphate, and $1 \%(\mathrm{v} / \mathrm{v})$ triethylene glycol) and boiled in water for $1 \mathrm{~h}$ to remove soluble substance and pectin. After centrifugation, the remaining pellet was washed with ultrapure water and dried at $80^{\circ} \mathrm{C}$. The pellet (holocellulose) weight was recorded as $W 2$. The dried pellet was digested in $1 \mathrm{~mL} 1 \mathrm{M} \mathrm{H}_{2} \mathrm{SO}_{4}$ solution for $1 \mathrm{~h}$ at $100^{\circ} \mathrm{C}$. Then, $1 \mathrm{~mL} 2 \mathrm{M} \mathrm{H}_{2} \mathrm{SO}_{4}$ solution was added, and the sample was boiled for $1 \mathrm{~h}$ to remove hemicellulose. Ultimately, the pellet was washed in ultrapure water and dried at $80^{\circ} \mathrm{C}$. The final pellet (cellulose) was weighed (W3). The contents of cellulose and hemicellulose in flesh samples were calculated with the following formulas: Cellulose $\left(\mathrm{mg} \cdot \mathrm{g}^{-1} \mathrm{FW}\right)=W 3 \times(W 1 / 20) / W 0$. Hemicellulose $\left(\mathrm{mg} \mathrm{g}^{-1} \mathrm{FW}\right)=(W 2-W 3) \times(W 1 / 20) / W 0, \mathrm{FW}$ means flesh weight of sample, and 20 is the initial weight $(20 \mathrm{mg})$ of dry pellet used for cellulose and hemicellulose determination.

2.5. Extraction and Quantification of Soluble Sugars and Organic Acids. The samples were prepared according to the method described by Niu et al. [31] with some modifications. Frozen juice sacs (about $5 \mathrm{~g}$ fresh weight) were ground in liquid nitrogen. Then $1.2 \mathrm{~g}$ of fine powder was transferred into a $10 \mathrm{~mL}$ tube and extracted in $6 \mathrm{~mL} 80 \%$ ethanol for $30 \mathrm{~min}$ at $37^{\circ} \mathrm{C}$. Samples were centrifuged at $15,000 \mathrm{~g}$ for $6 \mathrm{~min}$ at $4^{\circ} \mathrm{C}$. The residues were reextracted twice. The combined supernatants were placed in a volumetric flask and diluted to $25 \mathrm{~mL}$ with $80 \%$ ethanol. $3 \mathrm{~mL}$ of homogenized solution was dried at $60^{\circ} \mathrm{C}$ using a vacuum rotary evaporator. The dried extracts were dissolved in $3 \mathrm{~mL}$ ultrapure water, filtered through a $0.45-\mu \mathrm{m}$ hydroponic 
membrane, stored at $-80^{\circ} \mathrm{C}$, and used to determine soluble sugar. Meanwhile, $5 \mathrm{~mL}$ of homogenized solution was dried using the same method, dissolved in $1 \mathrm{~mL}$ ultrapure water, and then passed through a $0.45 \mu \mathrm{m}$ hydroponic membrane. This filtered solution was used for detecting the content of organic acid.

Determination of soluble sugar content was performed using ultra-high-performance liquid chromatography (UltiMate 3000, Dionex, California, USA), equipped with an ODS- $\mathrm{NH}_{2}$ column $(4.6 \times 250 \mathrm{~mm}, 5 \mu \mathrm{m})$ and CAD detector. $10 \mu \mathrm{L}$ of filtered solution of each sample was separated on a column at a temperature of $35^{\circ} \mathrm{C}$ and eluted with $70 \%$ acetonitrile at a flow rate of $1 \mathrm{~mL} \mathrm{~min}^{-1}$. D (+)-Sucrose, D-Fructose, and D (+)-Glucose were used as standard sugars (Solarbio, Beijing, China).

Quantification of organic acid was carried out using the same instrument. The chromatographic conditions are as follows [32]. $10 \mu \mathrm{L}$ of filtered solution of each sample was loaded on RD-C18 columns $(4.6 \times 250 \mathrm{~mm}, 5 \mu \mathrm{m})$ at $35^{\circ} \mathrm{C}$ and separated with mobile solution $\left(1.8 \mathrm{mM} \mathrm{KH}_{2} \mathrm{PO}_{4}, \mathrm{pH}\right.$ adjusted to 2.25 with phosphoric acid) at $0.8 \mathrm{~mL} \mathrm{~min}^{-1}$ flow rate. The absorbance of organic acids was recorded with an ultraviolet detector at $210 \mathrm{~nm}$ wavelength. Citric acid and malic acid standards were purchased from Solarbio, Beijing, China.

2.6. Statistical Analysis. Data were expressed as mean\pm standard error from three biological replicates. Differences between the two types of juice sacs were compared with Student's $t$-test at $p<0.05$. Multiple comparisons between stages were performed with one-way ANOVA based on Duncan's multiple range test at $p<0.05$. Statistical analyses were carried out with the SPSS 16.0 software.

\section{Results}

3.1. Changes in the Ultrastructure of Juice Sacs. In order to provide anatomic proof for juice sac granulation mechanisms, the subcellular structures of juice sacs were investigated during postharvest storage at room temperature. At the beginning of the storage period, the cytoplasm was uniformly distributed in the intracellular spaces of dorsal juice sacs (Figure 2(a)). The plasma membranes showed no damage. Particularly, a bright region was observed in the space between the plasma membrane and cell wall (Figure 2(b)). In septal juice sacs, the cytoplasm was distributed along the cell walls (Figure 2(c)), while the plasma membranes partially ruptured but vesicles were empty (Figure 2(d)).

After ten days of storage, organelles were distributed along the cell walls (Figure 3(a)) in dorsal juice sacs. Dense substances were scattered in the intracellular spaces (Figure 3(b), arrowhead) and also attached to the surface of vesicles adjacent to mitochondria. Particularly, the plasma membrane partially ruptured and the bright spaces between the plasma membrane and the cell walls disappeared (Figure 3(c)). In septal juice sacs, cytoplasm more closely attached to cell walls after ten days compared to the previous stage (Figure $3(\mathrm{~d})$ ). The plasma membranes were partially pulled away from the cell walls (Figure 3(d), open arrow). Some vesicles began accumulating dense substances; meanwhile, sparse dense substances were distributed in the intracellular spaces (Figures 3(e) and 3(f)).

At 20 days of storage, striking differences in structural characteristics were observed between the two types of juice sacs. In dorsal juice sacs, vesicles of various sizes appeared in the intracellular spaces; also, mitochondrion fission caused a slight increase in the number of mitochondria (Figures 4(a), 4(b), and 4(d)). The damage to the plasma membranes became severe, but the amount of cell wall substances was not obviously increased (Figure 4(c)). In septal juice sacs, numerous mitochondria and vesicles appeared in the intracellular spaces. Besides, a large number of small, filled vesicles were secreted from the Golgi apparatus adjacent to the mitochondria (Figures 4(e) and $4(\mathrm{f}))$. The plasma membranes ruptured and degraded (Figure $4(\mathrm{~g})$ ). At this stage, cell wall materials were distributed throughout the intercellular spaces and intracellular spaces (Figures 4(e), 4(f), 4(g) black arrowed head).

At 40 days of storage, mitochondria were prominent in the intracellular spaces of dorsal juice sacs (Figure 5(a)). Many small vesicles were observed concurrent with the mitochondria, but the Golgi apparatus did not appear in this type of juice sac (Figure 5(b)). The plasma membranes ruptured and degraded continuously (Figure 5(c)). It can be found that cell wall materials were uniformly distributed in the intracellular spaces (Figures 5(b) and 5(c)). In contrast, the number of mitochondria decreased, and they moved towards the cell walls in septal juice sacs (Figure 5(d)). Vesicles almost disappeared but long microfibrils accumulated in the intracellular spaces (Figure 5(e)). Cell wall materials were deposited on the surface of the cell walls (Figure 5(f), black arrowhead).

At the end of the storage period, mitochondria and vesicles disappeared in cells of both types of juice sacs (Figures 6(a) and 6(c)), and cell wall materials were continuously deposited on the surface of the cell walls (Figures 6(b) and 6(d)). Small black particles in the intracellular spaces in cells of dorsal juice sacs demonstrated that the cell wall components in this type of juice sac were different from those in septal juice sacs (Figure 6(b), black arrowhead).

Additionally, in both types of juice sacs, cell wall substances accumulated in the intercellular spaces throughout the whole period of storage.

3.2. Dynamics of Cell Wall Material Contents in Juice Sacs. In dorsal juice sacs, lignin contents showed no significant changes from 0 to 30 days of storage, peaked at 40 days $(p<0.05)$, and then decreased to similar levels as detected before day 30. Similarly, lignin contents were relatively steady in septal juice sacs from 0 to 30 days; however, they rapidly increased from 30 to 50 days, leading to significantly increased lignin contents at 40 and 50 days. Until day 60, lignin levels decreased, as seen before in dorsal juice sacs (Figure 7(a)). 


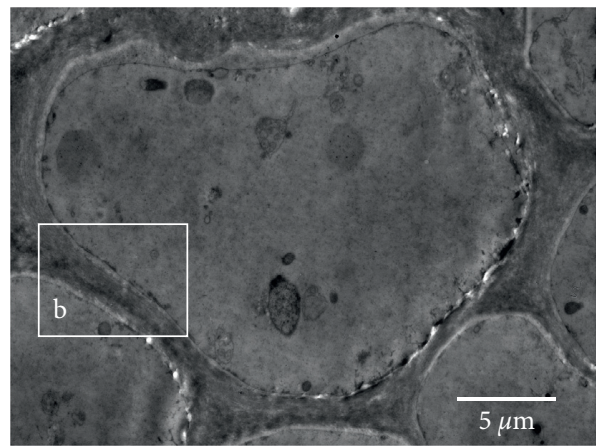

(a)

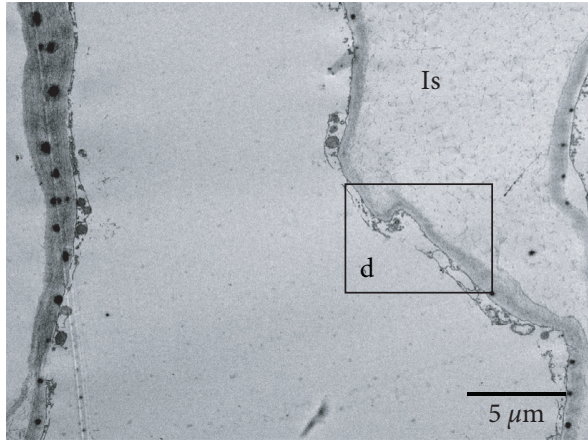

(c)

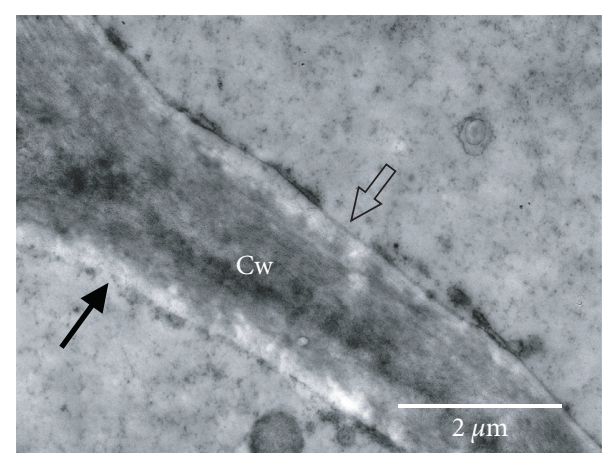

(b)

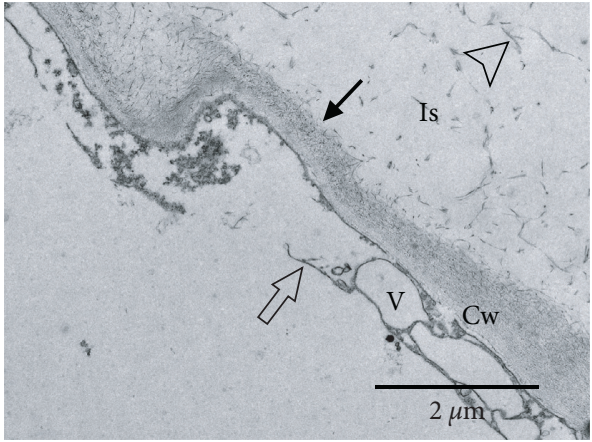

(d)

Figure 2: Transmission electron micrographs of cross sections of dorsal juice sac ( $a, b)$ and septal juice sac (c, d) of pummelo fruit stored for 0 days (the start of storage) at room temperature. (a) Overview of the cell structure of a dorsal juice sac. (b) Higher magnification micrograph of the region marked by a rectangle in (a). (c) Overview of the cell structure of a septal juice sac. (d) Higher magnification micrograph of the region marked by a rectangle in (c). $C w$ : cell wall, Is: intercellular space, $V$ : vesicle, arrow: space between the plasma membrane and the cell wall, open arrow: plasma membrane, and white arrowhead: microfibril.

The above results show a similar trend in the fluctuation of lignin contents in both types of juice sacs during postharvest storage. However, lignin contents in septal juice sacs were 4 -fold, 2 -fold, and 7 -fold higher than those in dorsal juice sacs at 30,40, and 60 days, respectively.

Cellulose contents in dorsal juice sacs remained relatively steady during postharvest storage. In contrast, in septal juice sacs, cellulose levels sharply increased at 40 days and remained high at 50 and 60 days of storage. Cellulose contents in septal juice sacs were significantly higher than those in dorsal juice sacs at 30 to 60 days (Figure 7(b)).

In dorsal juice sacs, hemicellulose was significantly accumulated at 10 and 60 days and has no apparent changes in the rest of stages. Hemicellulose in septal juice sacs remained relatively steady during postharvest storage but was significantly higher (1.6-fold) than that in dorsal juice sacs at 30 days (Figure $7(\mathrm{c})$ ).

3.3. Dynamics of Soluble Sugar Contents in Juice Sacs. As shown in Figure 8, sucrose contents of dorsal juice sacs showed no apparent fluctuation during the postharvest storage period. In contrast, sucrose levels in septal juice sacs showed substantial decreases after 30 days, which abolished the significant differences in sucrose levels that had been observed from day 0 to day 20 between the two types of juice sacs (Figure 8(a)).
During the whole storage period, fructose contents significantly increased in dorsal juice sacs but showed no significant changes in septal juice sacs. Statistical differences in fructose contents between the two types of juice sacs were investigated at 0,10 , and 30 days (Figure $8(\mathrm{~b})$ ).

Glucose levels showed no distinct changes for either type of juice sac during the postharvest storage; also they showed no apparent differences between the two types of juice sacs at each stage (Figure 8(c)).

\subsection{Dynamics of Organic Acid Contents in Juice Sacs.} Neither citric acid contents nor malic acid contents showed significant changes in either type of juice sac during storage. However, citric acid contents in dorsal juice sacs were much higher than those in septal juice sacs at 10 and 60 days, while malic acid contents in dorsal juice sacs were significantly lower compared to those in septal juice sacs at 40 and 60 days (Figures 9(a) and 9(b)).

\section{Discussion}

4.1. Two Types of Juice Sacs with Different Degrees of Granulation. In this study, the results showed that cell wall components accumulate differently in two types of juice sacs. Lignin and hemicellulose transiently accumulated in dorsal juice sacs at certain stages of postharvest storage. In 


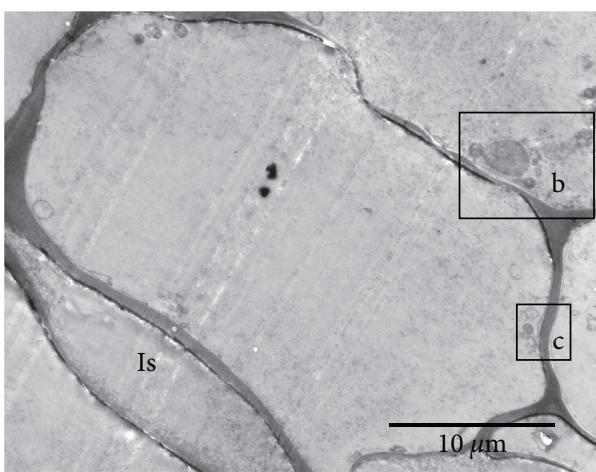

(a)

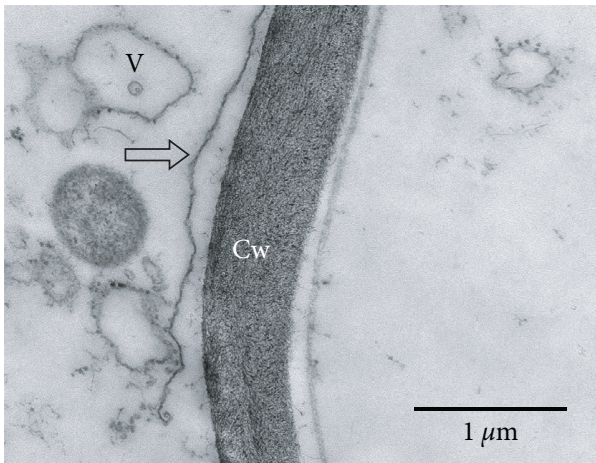

(c)

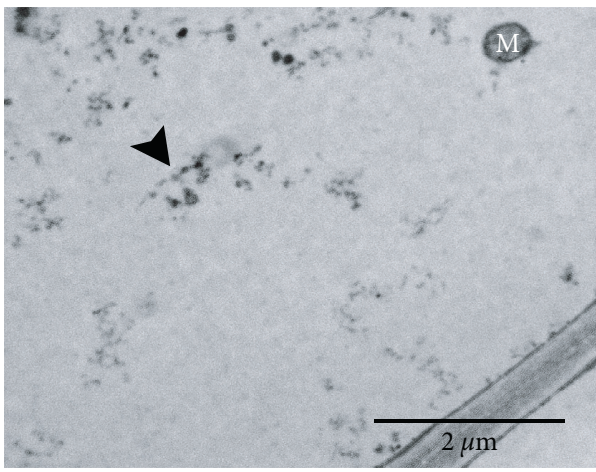

(e)

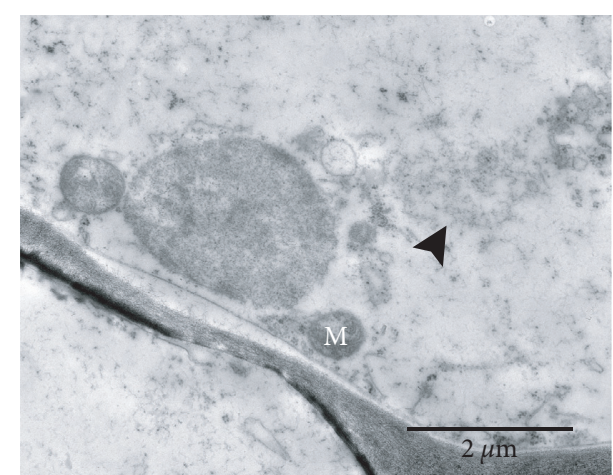

(b)

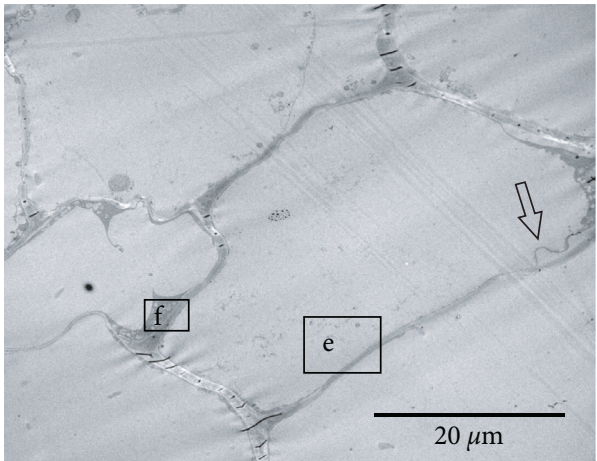

(d)

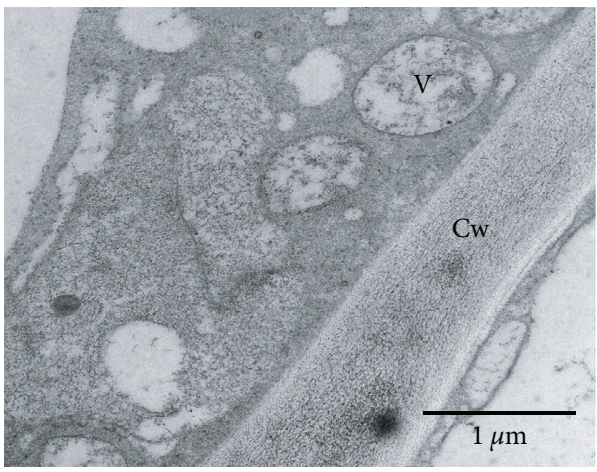

(f)

Figure 3: Transmission electron micrographs of cross sections of dorsal juice sac $(\mathrm{a}-\mathrm{c}$ ) and septal juice sac (d-f) of pummelo fruit stored for ten days at room temperature. (a) Overview of the cell structure of a dorsal juice sac. (b, c) Magnified micrographs of the regions marked by rectangles in (a). Note the distribution pattern of organelles and the occurrence of cell wall materials in the intracellular spaces. (d) Overview of the cell structure of a septal juice sac. (e, f) Higher magnification micrographs of the regions marked by rectangles in (d). Note cell wall materials distributed in the intracellular space and filled vesicles. $C w$ : cell wall, $M$ : mitochondrion, $V$ : vesicle, Is: intercellular space, open arrow: plasma membrane, and black arrowhead: dense substances.

contrast, lignin and cellulose contents significantly increased in septal juice sacs from day 40 of postharvest storage. These results indicate that lignin and hemicellulose might be degraded in dorsal juice sacs. Cellulose contents in dorsal juice sacs and hemicellulose contents in septal juice sacs showed no significant differences during postharvest storage. Lignin, cellulose, and hemicellulose contents in septal juice sacs began to significantly exceed those of dorsal juice sacs at 30 days of storage. However, in contrast to cellulose and lignin, the significant differences in hemicellulose levels between the two types of juice sacs disappeared after 30 days. Taken together, these findings suggest that lignin and cellulose are the main contributors to the difference in the granulation degree of the two types of juice sacs.

4.2. Changes in Soluble Sugar Contents Are Connected with Cell Wall Material Accumulation. In septal juice sacs, sucrose contents significantly decreased from 30 to 60 days, while lignin and cellulose were primarily accumulated after 30 days. This suggests that sucrose degradation starts slightly before cell wall material accumulation. Sucrose can provide the primary components for cellulose and lignin synthesis. Invertase and sucrose synthase are two distinct enzymes that 

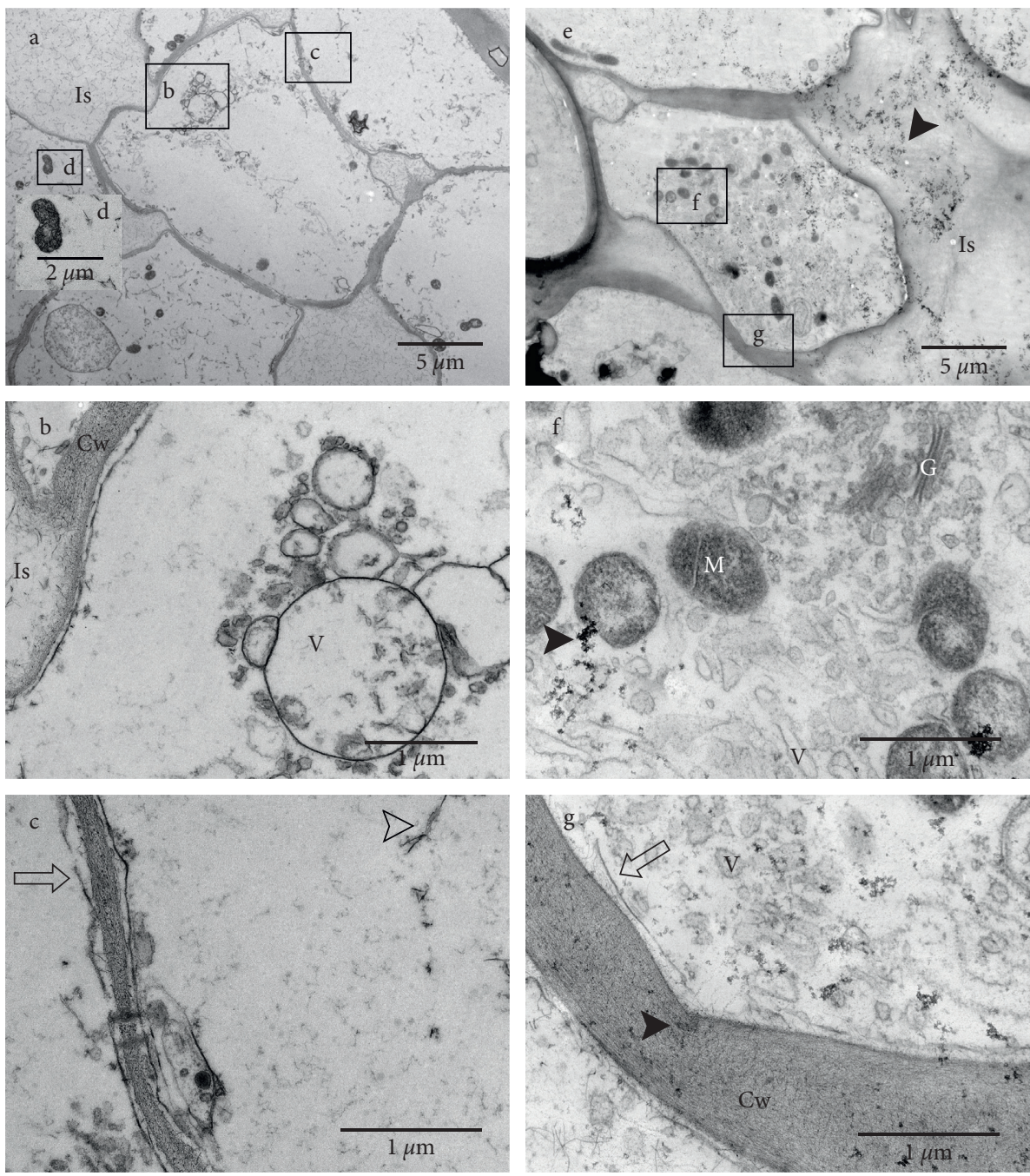

Figure 4: Transmission electron micrographs of cross sections of dorsal juice sac (a-d) and septal juice sac (e-g) of pummelo fruit stored for 20 days at room temperature. (a) Overview of the cell structure of a dorsal juice sac. (b-d) Higher magnification micrographs of the regions marked by rectangles in a. Note mitochondrial fission in d. (e) Overview of the cell structure of a septal juice sac. (f and g) Higher magnification micrographs of the regions marked by rectangles in e. Golgi apparatus appeared and the number of mitochondria and vesicles sharply increased in the intracellular space. $C w$ : cell wall, G: Golgi apparatus, $M$ : mitochondrion, Is: intercellular space, V: vesicle, open arrow: plasma membrane, black arrowhead: dense substances, and white arrowhead: microfibril.

catalyze the conversion of sucrose into UDP-glucose. UDPglucose is a direct substance for cellulose synthesis [33]. Invertase activity is positively correlated with UDP-glucose and cellulose contents [34-36]. Sucrose synthase is an enzyme that catalyzes the reversible conversion of sucrose and uridine diphosphate (UDP) into fructose and UDP-glucose [37]. In cotton fiber cells, sucrose synthase was found to play a critical role in fiber initiation and early elongation and to be involved in rapid cellulose synthesis at the later development stages [38]. Also, the glycolysis pathway is linked with the polysaccharide and lignin synthesis pathways during protoxylem vessel development in tobacco [39]. Therefore, it is assumable that the carbon source used for lignin synthesis is partially derived from sucrose degradation. In this study, the cellulose and lignin contents increased immediately just after the decline of sucrose contents in septal juice sacs, indicating that sucrose degradation is activated earlier than cellulose synthesis.

In dorsal juice sacs, fructose contents significantly increased from 10 to 60 days, while sucrose and glucose levels did not change. In rice, fructose availability can reverse the sucrose degradation reaction into the sucrose synthesis reaction mediated by sucrose synthase [40]. In this study, increased fructose contents may provide a feedback effect on suppressing sucrose degradation reaction and consequently any significant changes in the sucrose contents can be 


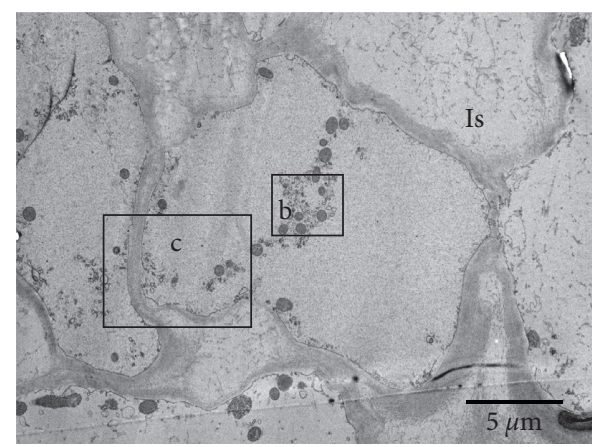

(a)

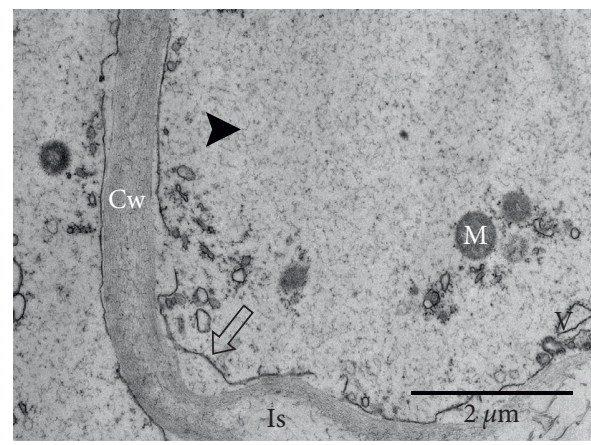

(c)

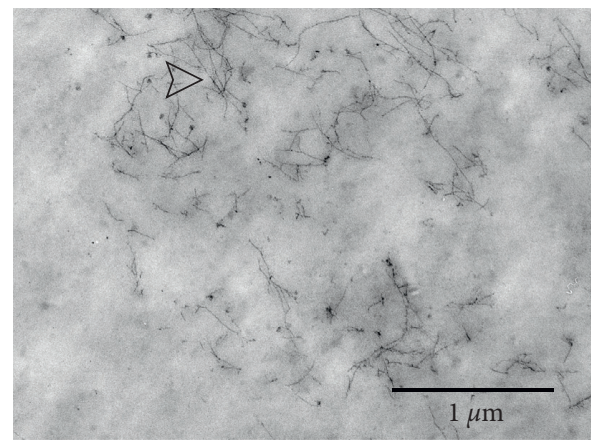

(e)

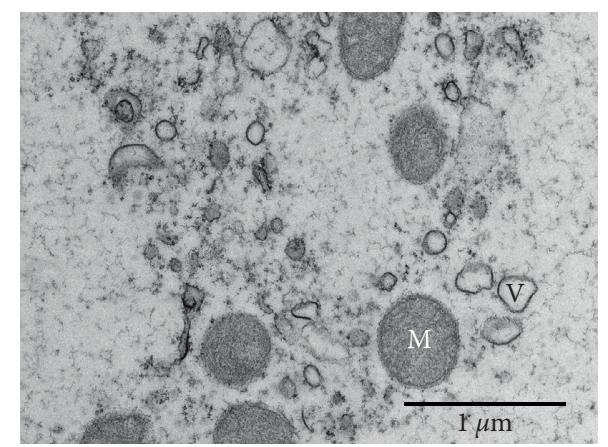

(b)

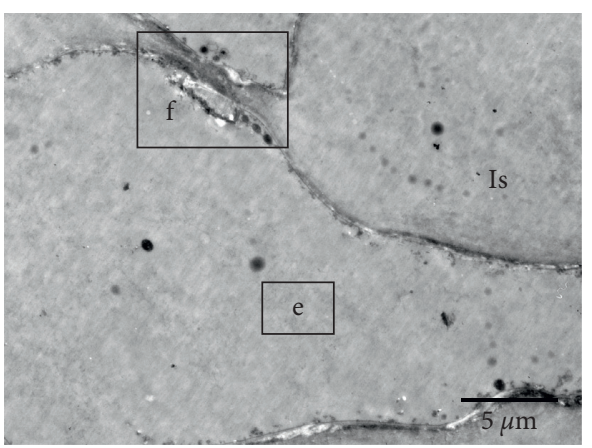

(d)

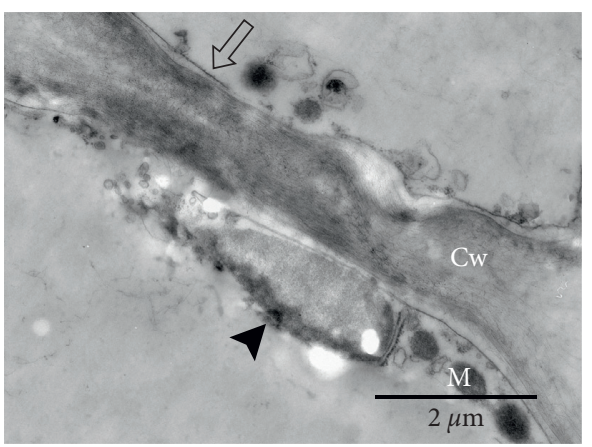

(f)

Figure 5: Transmission electron micrographs of cross sections of dorsal juice sac $(\mathrm{a}-\mathrm{c})$ and septal juice sac $(\mathrm{d}-\mathrm{f})$ of pummelo fruit stored for 40 days at room temperature. (a) Overview of the cell structure of a dorsal juice sac. (b, c) Higher magnification micrographs of the regions marked by rectangles in (a). Note the concurrent increases in the abundance of mitochondria and cell wall materials. (d) Overview of the cell structure of a septal juice sac. (e, f) Higher magnification micrographs of the regions marked by rectangles in (d). Note long microfibrils in the intracellular spaces and secondary cell wall thickening. $C w$ : cell wall, $M$ : mitochondrion, $V$ : vesicle, Is: intercellular space, open arrow: plasma membrane, white arrowhead: microfibril, and black arrowhead: cell wall materials.

detected in dorsal juice sacs. However, further experiment needs to be carried out to determine the reason for increased fructose in dorsal juice sacs.

\subsection{The Possible Roles of Organic Acids Involved in Regulating} Juice Sac Granulation. Organic acid contents detected in both types of juice sacs remained relatively steady during the whole storage period. It is well known that malic acid and citric acid are metabolites in tricarboxylic acid cycle [41]. Malate dehydrogenase catalyzes the conversion of malic acid to oxaloacetate [42]. Subsequently, oxaloacetate is used as a substance to produce citric acid [43]. In pummelo fruits, enzymes $\left(\mathrm{H}^{+}\right.$-ATPase, $\mathrm{Ca}^{2+}$-ATPase, $\mathrm{Mg}^{2+}$-ATPase, cytochrome $\mathrm{C}$ oxidase, succinate dehydrogenase, and malate dehydrogenase) that participated in energy metabolism were markedly maintained by chitosan coating, which was accompanied by decreased cellulose content in pulp, alleviated postharvest senescence, and reduced energy depletion of fruits [44]. Based on findings reported by Chen et al. [44], it can be deduced that markedly maintained malate dehydrogenase in pummelo fruits may act as a mediator for regulation of malic acid and citric acid contents. The findings in this study combined with the reports suggest that malic acid and citric acid contents remain constant as much as possible in response to juice sac granulation. 


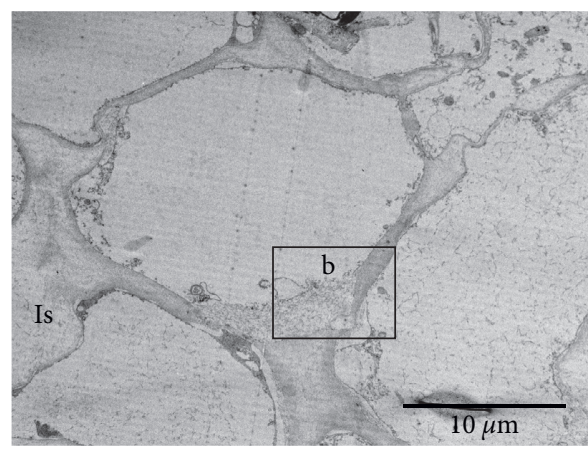

(a)

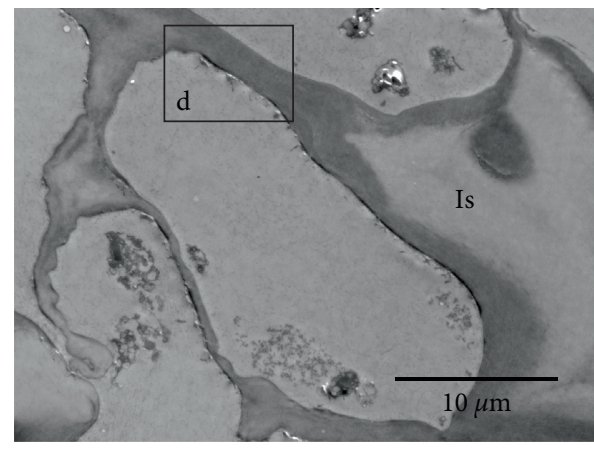

(c)

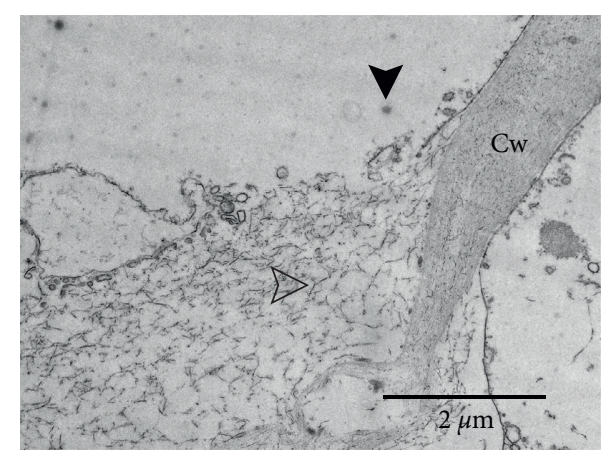

(b)

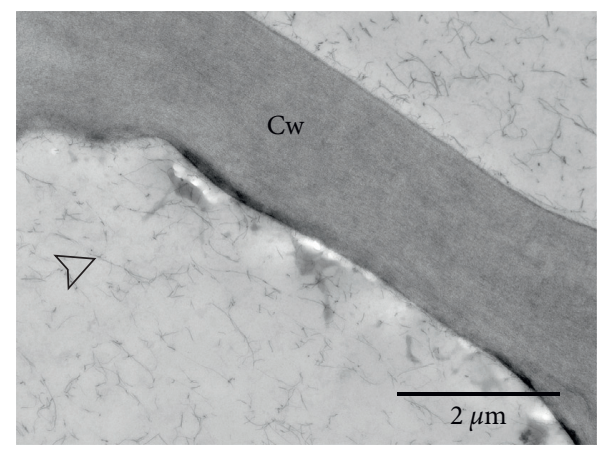

(d)

Figure 6: Transmission electron micrographs of cross sections of dorsal juice sac ( $a, b)$ and septal juice sac (c, d) of pummelo fruit stored for 60 days at room temperature. (a) Overview of the cell structure of a dorsal juice sac. (b) Higher magnification micrograph of the region marked by a rectangle in (a). (c) Overview of the cell structure of a septal juice sac. (d) Higher magnification micrograph of the region marked by a rectangle in (c). Cw: cell wall, Is: intercellular space, white arrowhead: microfibril, and black arrowhead: particles of cell wall substances.

4.4. Plasma Membrane Rupture Induces Cell Wall Material Synthesis. In this study, the damage to plasma membrane is accompanied by cell wall material accumualtion in juice sacs. Lipid peroxidation leads to decreased plasma membrane integrity and can be detected by malonaldehyde and $\mathrm{H}_{2} \mathrm{O}_{2}$ production $[45,46]$. Considering the finding that $\mathrm{H}_{2} \mathrm{O}_{2}$ is accumulated in granulated juice sacs [16], combined with the ultrastructure obtained in this study, it appears that the loss of plasma membrane integrity may act as an early signal for juice sac granulation.

\subsection{An Increase in the Number of Mitochondria Accelerates} Cell Wall Material Accumulation. After ten days of storage, plasma membrane ruptures continuously increased for the rest of the storage period. However, this is not the key factor inducing considerable accumulation of cell wall materials and noticeable decreases in soluble sugar contents. This conclusion is supported by the findings that TEM images of dorsal juice sacs showed an increased number of vesicles and damage of the plasma membranes at day 20, which did not lead to significant increases in cell wall material contents at this stage. Until the number of mitochondria sharply increased at 40 days, cell wall substance was accumulated mainly in dorsal juice sacs. Furthermore, in septal juice sacs, dramatical increase in the number of mitochondria was accompanied by distinct distribution of cell wall materials.
Additionally, lignin, cellulose, and hemicellulose contents in septal juice sacs began to significantly exceed those of dorsal juice sacs at 30 days of storage (just after the number of mitochondria greatly increased at 20 days), providing further proof of the key role of mitochondria in regulating carbon source partitioning to cell wall material synthesis.

In this study, the Golgi apparatus and/or numerous vesicles occurred simultaneously with the number of $\mathrm{mi}-$ tochondria in juice sacs at specific stages. In line with this finding, many reports have shown that cell wall material accumulation, at least in part, depends on the Golgi apparatus and vesicles. Suppressing vesicle secretion from the Golgi apparatus, cellulose contents decrease in whole plants of rice [47]. Moreover, enzymes or proteins involved in cell wall material synthesis, such as xylan synthase complexes [27], xylan deacetylases [48], STELLO1, 2 (proteins regulating the secretion and activity of cellulose synthase) [49], and cell wall materials like p-glucocoumaryl alcohol [50], xyloglucan [51], and xylan [52], have been detected in Golgi and/or vesicles in various plant tissues (e.g., root, internode, differentiating xylem). In this study, the occurrence of Golgi apparatus and/or numerous vesicles was associated with a high accumulation of cell wall materials in juice sacs, especially lignin and cellulose, which indicates that Golgi and vesicles are also essential organelles involved in the development of juice sac granulation, although their roles link to the occurrence of numerous mitochondria. 


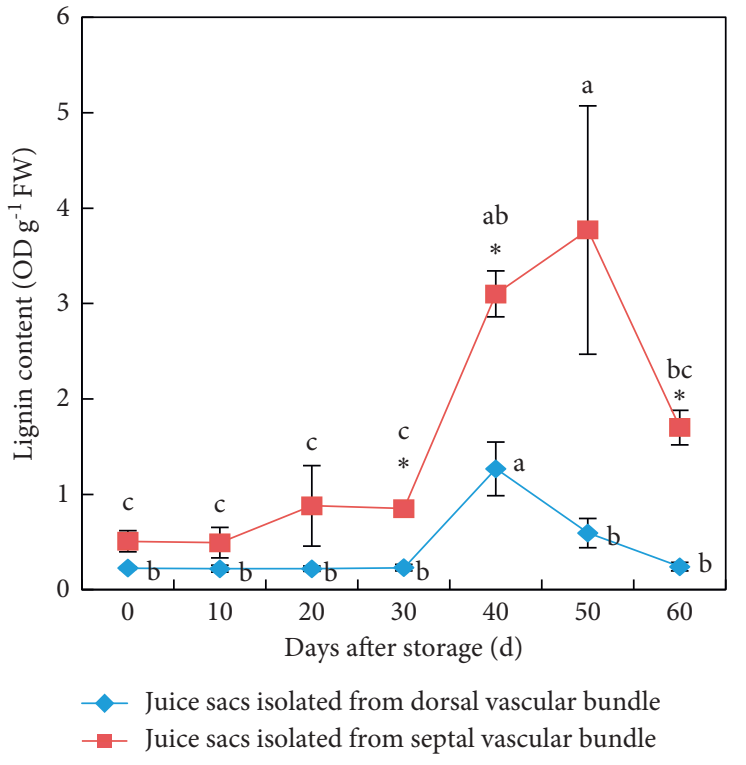

(a)

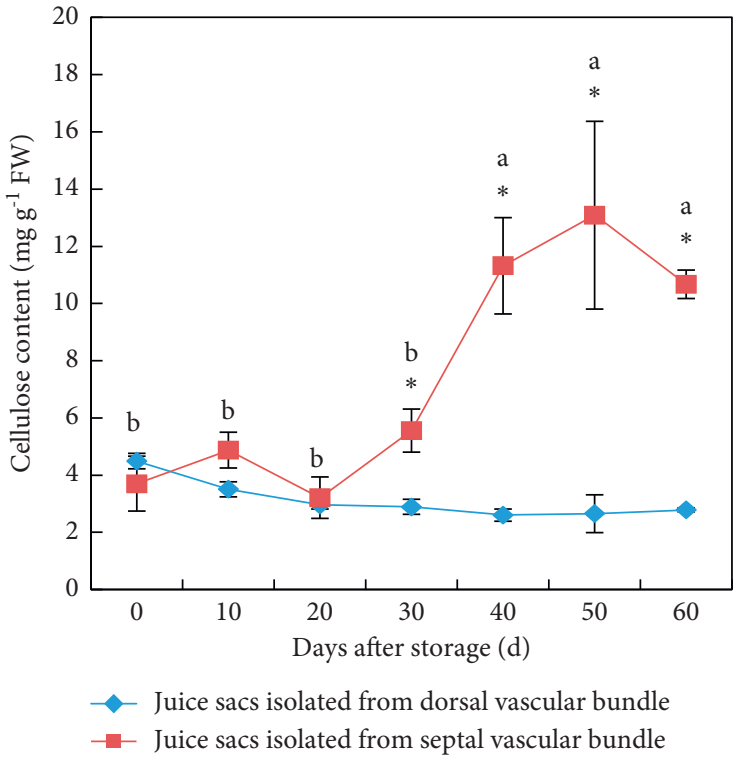

(b)

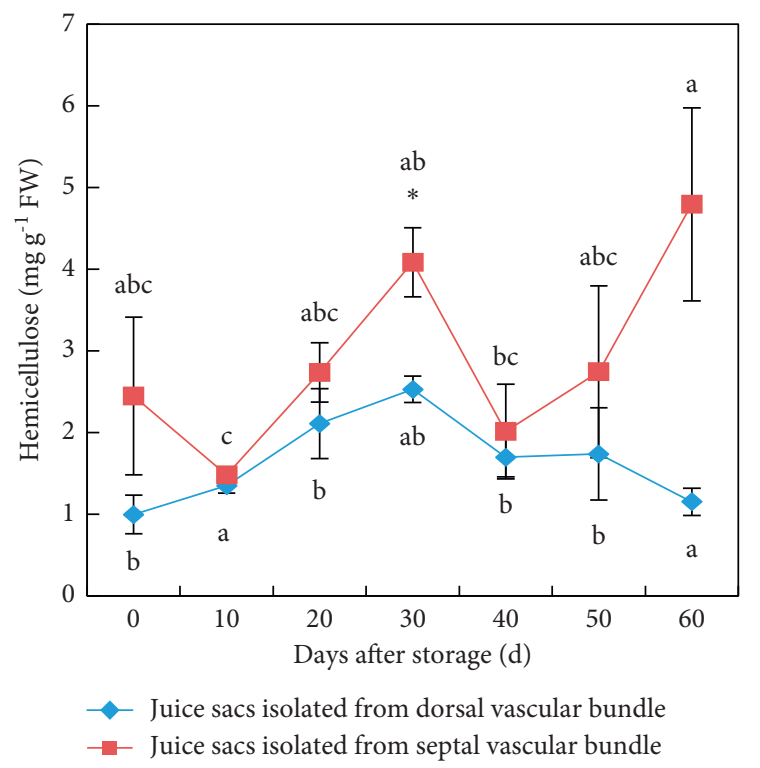

(c)

Figure 7: Cell wall contents in dorsal juice sacs and septal juice sacs during postharvest storage. (a) Lignin absorbance in juice sacs. (b) Cellulose contents in juice sacs. (c) Hemicellulose contents in juice sacs. The $x$-axis represents the storage time of fruits; the $y$-axis represents cell wall material levels. Error bars represent the standard errors derived from three biological replicates. The lowercase letters represent the differences among stages. Asterisks represent the significant differences between the two types of juice sacs at each stage.

Mitochondria are versatile organelles in plants. It is well known that the tricarboxylic acid cycle, a pathway for ultimate degradation of sugar, acid, and lipid (providing intermediate production and energy), is located in mitochondria [53]. Also, transcriptome profiles revealed that energy metabolism mediated by mitochondria plays a vital role in cotton fiber elongation [54]. Furthermore, it was found that invertases are located at mitochondria in Jerusalem artichoke (Helianthus tuberosus L.) tubers [55]. Knockdown of the genes encoding for alkaline/neutral invertases (A/N-Invs) localized in mitochondria led to reduced oxygen consumption in Arabidopsis Invs mutants [56].
Additionally, oxygen uptake in granulated juice sacs of freshly harvested "Lee" tangelos, stored "Dancy" tangerine, and stored "Marsh" grapefruits was 2- to 3-fold higher when compared with that in normal juice sacs [57]. Combined with our findings that mitochondria are closely connected with evident cell wall material accumulation during juice sac granulation, it can be deduced that mitochondria may play a key role in accelerating sucrose degradation in granulated juice sacs.

On the other hand, mitochondria are also an important site for reactive oxygen species (ROS) synthesis [58-60]. $\mathrm{H}_{2} \mathrm{O}_{2}$ has been associated with juice sac granulation and 


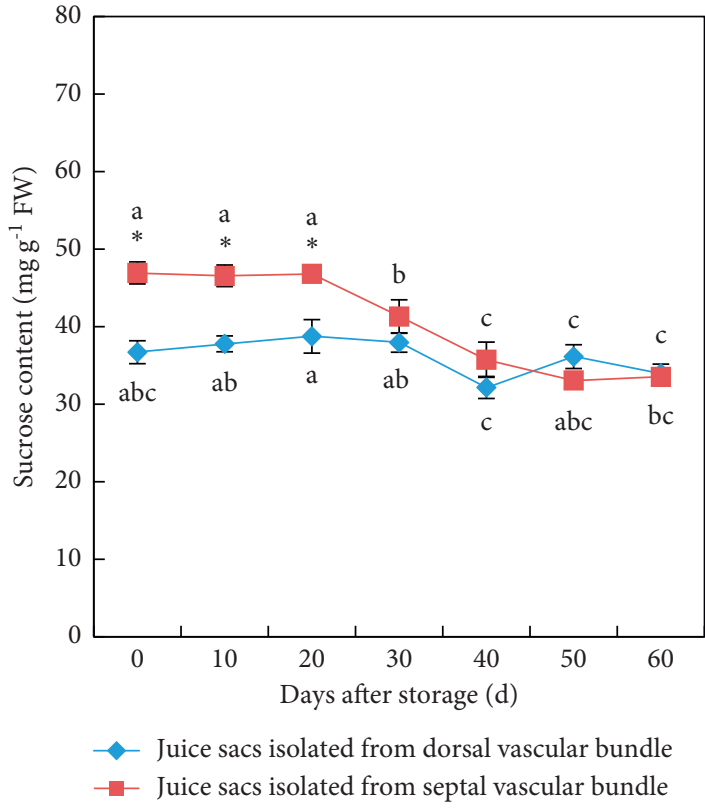

(a)

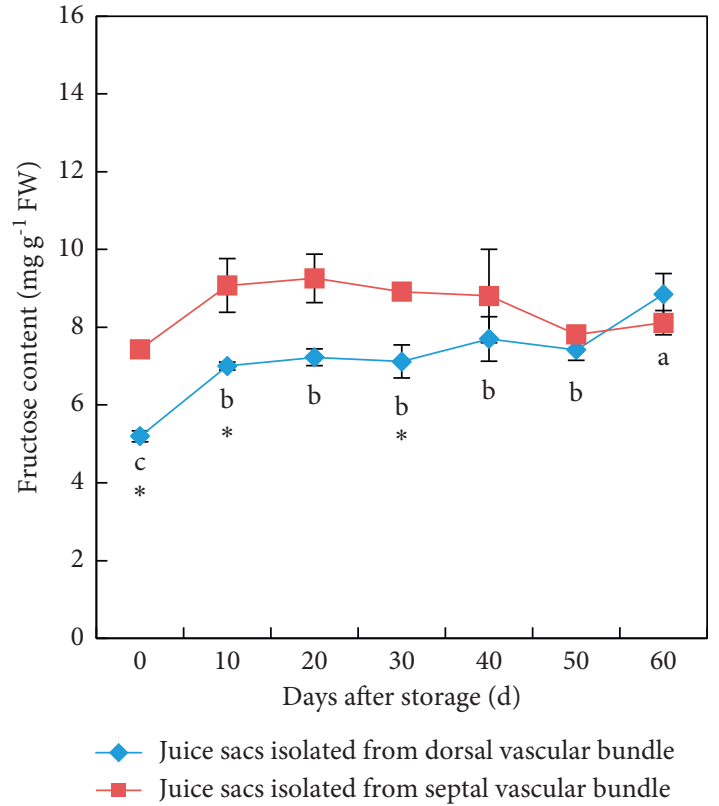

(b)

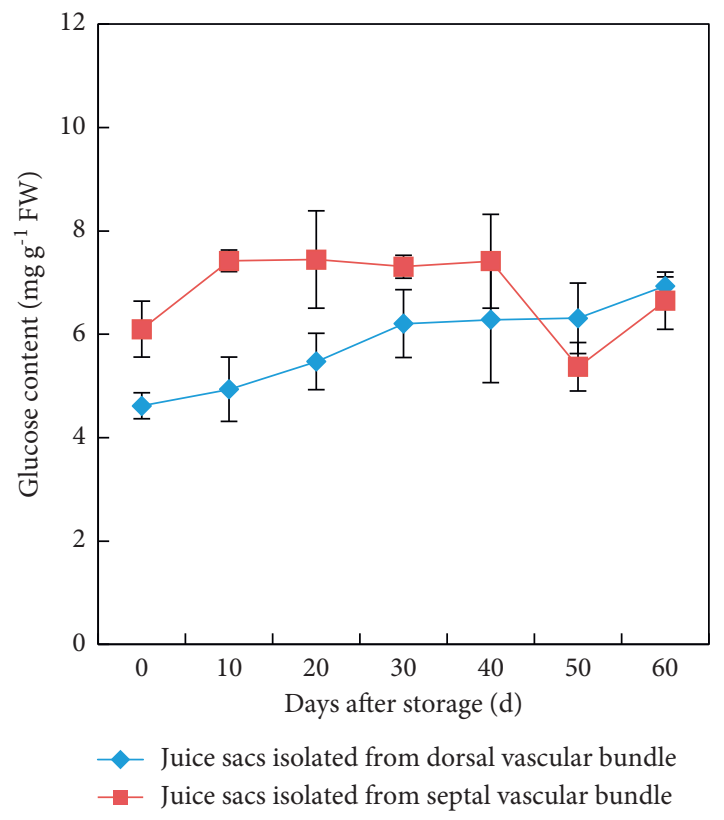

(c)

Figure 8: Soluble sugar contents in dorsal juice sacs and septal juice sacs during postharvest storage. (a) Sucrose contents in juice sacs. (b) Fructose contents in juice sacs. (c) Glucose contents in juice sacs. The $x$-axis represents the storage time of fruits; the $y$-axis represents soluble sugar content. Error bars represent the standard errors derived from three biological replicates. The lowercase letters represent the significant differences among stages. Asterisks represent the significant differences between the two types of juice sacs at each stage.

positively correlated with xylem lignification [22] and cellulose accumulation in plants growing in salt stress conditions [61]. Although the prominent role of $\mathrm{H}_{2} \mathrm{O}_{2}$ in cell wall material accumulation is clear, it is uncertain whether $\mathrm{H}_{2} \mathrm{O}_{2}$ is generated from mitochondria during juice sac granulation. Therefore, the detailed roles of mitochondria in regulating juice sac granulation need further research. It has been shown that mitochondrial fission and fusion can be imbalanced due to the cell environment, which leads to fluctuations in mitochondrion numbers [62]. Some evidence also demonstrated that ROS accumulation promotes mitochondrial fission in animal cells [63-65]; however, whether ROS participates in regulating mitochondrion dynamics in plant cells is elusive. In the future, suppressing the increase in mitochondria could be a promising approach for controlling juice sac granulation of pummelo fruits. 


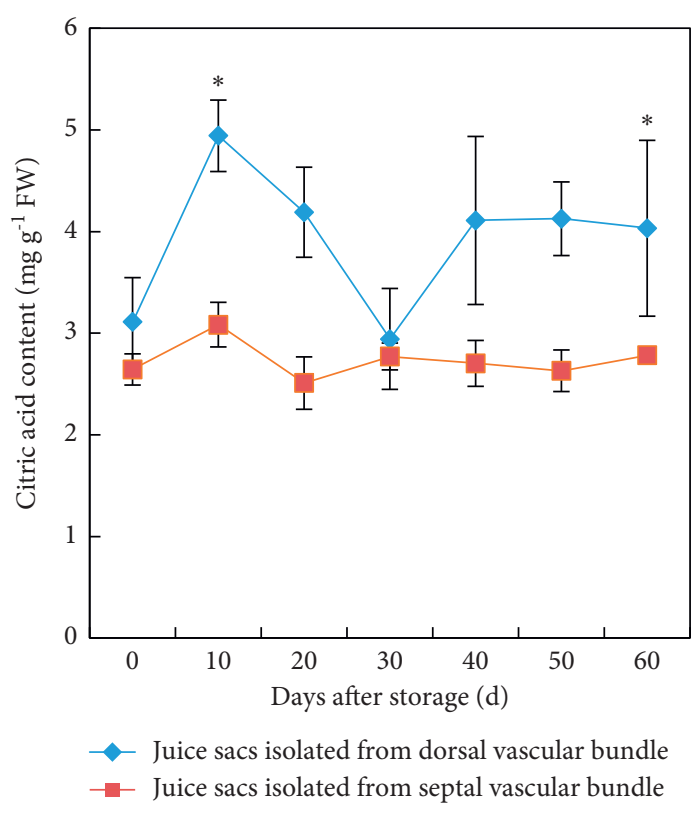

(a)

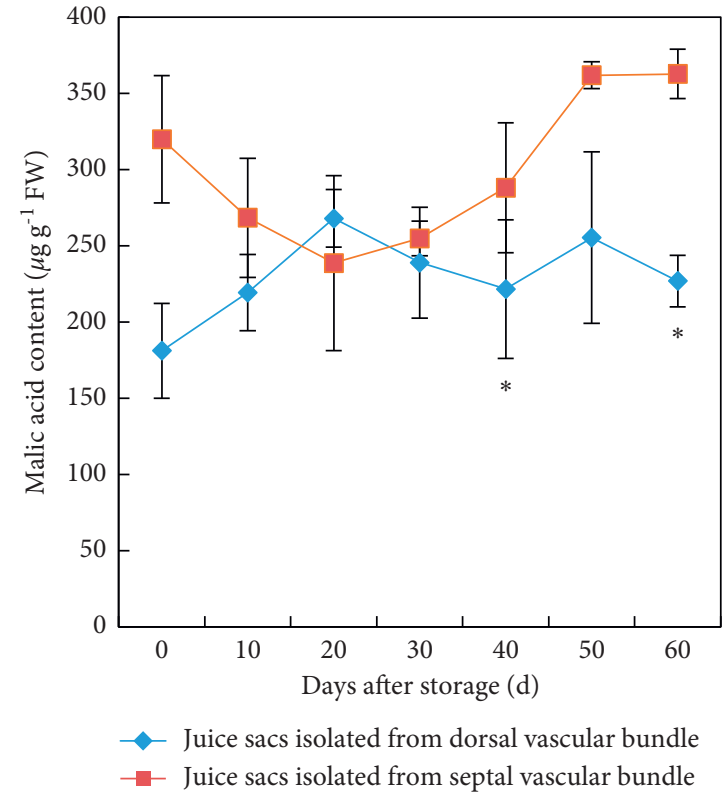

(b)

Figure 9: Organic acid contents in dorsal juice sacs and septal juice sacs during postharvest storage. (a) Citric acid contents in juice sacs. (b) Malic acid contents in juice sacs. The $x$-axis represents the storage time of fruits; the $y$-axis represents organic acid content. Error bars represent the standard errors derived from three biological replicates. Asterisks represent the significant differences between the two types of juice sacs at each stage.

4.6. Cell Wall Material Accumulation in the Intracellular and the Intercellular Space of Juice Sac Cells. In both types of juice sacs, cell wall material accumulation in the intercellular space was earlier compared to that in the intracellular space. However, this did not lead to immediate significant increases in cell wall material contents in juice sacs. These results suggest that the abundance of cell wall materials synthesized in the intracellular space of juice sac cells is closely connected with the degree of juice sac granulation.

\section{Conclusions}

Cell wall material accumulation in dorsal juice sacs differs from that in septal juice sacs. Lignin and hemicellulose are the major cell wall components synthesized in dorsal juice sacs, and the transient increases in their levels indicate that their degradation reaction should not be ignored. In contrast, lignin and cellulose are the two kinds of cell wall compounds contributing to cell wall substance accumulation in septal juice sacs. The significant increases in their levels begin to be observed at 40 days and prolong to the end of storage (except lignin content at 60 days). Although cell wall component contents are also distinctly increased in dorsal juice sacs at specific stages, their levels are significantly lower compared to septal juice sacs at 30 days and the following stages (no apparent differences can be detected before 30 days). Organic acid contents have no noticeable changes in either type of juice sac during postharvest storage. Soluble sugar levels exhibited distinct differences in juice sacs during the whole period of storage. The significant decreases in sucrose contents (at 30 days) prior to the obvious increases in lignin and cellulose levels (at 40 days) in septal juice sacs suggest that sucrose degradation is the key step for providing enough carbon for cell wall component synthesis. In contrast, sucrose contents in dorsal juice sacs remain constant during the postharvest storage. However, fructose contents are significantly elevated from 10 to 60 days. Therefore, it could be deduced that the increased fructose contents may have a feedback effect on suppressing sucrose degradation. Accordingly, cell wall material is less accumulated.

The comprehensive analysis of TEM images of the two types of juice sacs found that, until the number of mitochondria largely increases, cell wall materials are significantly accumulated, although plasma membrane rupture and accumulation of vesicles occur in earlier stages. Taken together, plasma membrane rupture may provide a signal for induction of juice sac granulation, while mitochondria play a critical role in regulating sugar carbon flux partitioning for cell wall material synthesis.

\section{Data Availability}

All data used to support the findings of this study are included within the paper.

\section{Conflicts of Interest}

The authors declare that they have no conflicts of interest. 


\section{Acknowledgments}

This study was supported by the Science Foundation for Young Scholars from Fujian Academy of Agricultural Sciences (Grant no. YC-2016-6), Regional Development Fund from Fujian Provincial Science and Technology Department (Grant no. 2018N3004), and Scientific-Basic Special Fund for Research Institutes in the Public Interests from Fujian Provincial Science and Technology Department (Grants nos. 2017R1013-3 and 2020R10280014).

\section{References}

[1] R. R. Sharma, R. Singh, and S. K. Saxena, "Characteristics of citrus fruits in relation to granulation," Scientia Horticulturae, vol. 111, no. 1, pp. 91-96, 2006.

[2] J. Ortúzar, L. Barrales, L. Barrales, I. Peña, P. Carmona, and G. Valdivieso, "Influence of on-tree and cold storage on quality of Lane Late and Navelate oranges in Chile," Ciencia e investigación agraria, vol. 30, no. 1, pp. 27-38, 2003.

[3] Z. Y. Zhang, Z. N. Xie, and W. B. Xu, "Anatomical observation on differentiation and granulation processes of juice sacs in Citrus grandis," Acta Botanica Sinica, vol. 41, pp. 16-19, 1999.

[4] D. M. Pan, G. H. Zheng, G. X. Chen et al., "Analysis of the reasons caused granulation of juice sacs in Guanximiyou pomelo variety," Journal of Fruit Science, vol. 16, pp. 202-209, 1999.

[5] B. Xiong, Z. H. Wang, and D. D. Shi, "Relationship between granulation and materials of cell wall, polyamine in Huangguogan fruit," Acta Agriculturae Boreali-Simica, vol. 29, pp. 239-242, 2014.

[6] W. B. Sinclair and V. A. Jolliffe, "Chemical changes in the juice vesicles of granulated valencia oranges," Journal of Food Science, vol. 26, no. 3, pp. 276-282, 1961.

[7] X.-Y. Wang, P. Wang, Y.-P. Qi et al., "Effects of granulation on organic acid metabolism and its relation to mineral elements in Citrus grandis juice sacs," Food Chemistry, vol. 145, no. 15, pp. 984-990, 2014.

[8] S. Yao, Q. Cao, J. Xie, L. Deng, and K. Zeng, "Alteration of sugar and organic acid metabolism in postharvest granulation of Ponkan fruit revealed by transcriptome profiling," Postharvest Biology and Technology, vol. 139, pp. 2-11, 2018.

[9] A. R. Barceló, L. V. Gómez Ros, C. Gabaldón et al., "Basic peroxidases: the gateway for lignin evolution?" Phytochemistry Reviews, vol. 3, no. 1-2, pp. 61-78, 2004.

[10] R. R. Sharma, O. P. Awasthi, and K. Kumar, "Pattern of phenolic content, antioxidant activity and senescence-related enzymes in granulated vs non-granulated juice-sacs of "Kinnow" Mandarin (Citrus nobilis x C. deliciosa)," Journal of Food Science \& Technology, vol. 53, no. 3, pp. 1525-1530, 2016.

[11] T. F. Pan, X. L. Zhu, D. M. Pan, and Z. X. Zeng, "Effects of low temperature on the relationship between granulation and lignin metabolism in pummelo fruit during storage," Chinese Journal of Topical Crops, vol. 34, no. 4, pp. 710-714, 2013.

[12] W. Q. She, X. L. Zhao, D. M. Pan, and H. T. Lin, "Relationship between cell wall metabolism and fruit juicy sac granulation during fruit mature stage of pummelo [Citrus grandis (L.) Osbeck "Guanxi-miyou"]," Journal of Tropical and Subtropical Botany, vol. 16, no. 6, pp. 545-550, 2008.

[13] M. Bevan, D. Shufflebottom, K. Edwards, R. Jefferson, and W. Schuch, "Tissue- and cell-specific activity of a phenylalanine ammonia-lyase promoter in transgenic plants," The EMBO Journal, vol. 8, no. 7, pp. 1899-1906, 1989.
[14] C. Feuillet, V. Lauvergeat, C. Deswarte, G. Pilate, A. Boudet, and J. Grima-Pettenati, "Tissue- and cell-specific expression of a cinnamyl alcohol dehydrogenase promoter in transgenic poplar plants," Plant Molecular Biology, vol. 27, no. 4, pp. 651-667, 1995.

[15] L. L. Shan, X. Li, P. Wang et al., "Characterization of cDNAs associated with lignification and their expression profiles in loquat fruit with different lignin accumulation," Planta, vol. 227, no. 6, pp. 1243-1254, 2008.

[16] W. Q. She, D. M. Pan, and H. T. Lin, "Relationship between granulation and active oxygen metabolism of juice sac in pummelo fruit during maturation," Scientia Agricultura Sinica, vol. 42, no. 5, pp. 1737-1743, 2009.

[17] X. Y. Wang, Y. F. Xi, and Y. J. Wang, "Endogenous hormones in relation to g ranulation of ponkan Mandarin fruit," Acta Agriculturae Zhejiangensis, vol. 9, no. 2, pp. 103-105, 1997.

[18] J. J. Zhao, "Study on the changes of endogenous hormone contents in pomelo fruit growth process," Master Degree of Dissertation, Fujian Agriculture and Forestry University, Fuzhou, China, 2013.

[19] N. Jia, J. Liu, Y. Sun et al., "Citrus sinensis MYB transcription factors CsMYB330 and CsMYB308 regulate fruit juice sac lignification through fine-tuning expression of the Cs4CL1 gene," Plant Science, vol. 277, pp. 334-343, 2018.

[20] N. Jia, J. Liu, P. Tan et al., "Citrus sinensis MYB transcription factor CsMYB85 induce fruit juice sac lignification through interaction with other CsMYB transcription factors," Frontiers of Plant Science, vol. 10, p. 213, 2019.

[21] X. Li, Y. F. Chai, H. B. Yang et al., "Isolation and comparative proteomic analysis of mitochondria from the pulp of ripening citrus fruit," Horticulture Research, vol. 8, p. 31, 2021.

[22] C. G. Smith, M. W. Rodgers, A. Zimmerlin, D. Ferdinando, and G. P. Bolwell, "Tissue and subcellular immunolocalisation of enzymes of lignin synthesis in differentiating and wounded hypocotyl tissue of French bean (Phaseolus vulgaris L.)," Planta, vol. 192, no. 2, pp. 155-164, 1994.

[23] Z. C. Xu and Y. Kong, "Genome-wide identification, subcellular localization and gene expression analysis of the members of CESA gene family in common tobacco (Nicotiana tabacum L.)," Hereditas, vol. 39, no. 6, pp. 512-524, 2017.

[24] R. Zhong, Q. Teng, M. Haghighat et al., "Cytosol-localized UDP-xylose synthases provide the major source of UDPxylose for the biosynthesis of xylan and xyloglucan," Plant and Cell Physiology, vol. 58, no. 1, pp. 156-174, 2017.

[25] N. Jiang, R. E. Wiemels, A. Soya, R. Whitley, M. Held, and A. Faik, "Composition, assembly, and trafficking of a wheat xylan synthase complex," Plant Physiology, vol. 170, no. 4, pp. 1999-2023, 2016.

[26] A. Ros Barceló, "Xylem parenchyma cells deliver the $\mathrm{H}_{2} \mathrm{O}_{2}$ necessary for lignification in differentiating xylem vessels," Planta, vol. 220, no. 5, pp. 747-756, 2005.

[27] L. L. Orcid, Y. Bi, S. G. Li, H. L. Xue, Z. Zhang, and D. B. Prusky, "Early defense responses involved in mitochondrial energy metabolism and reactive oxygen species accumulation in harvested muskmelons infected by Trichothecium roseum," Journal of Agricultural and Food Chemistry, vol. 67, no. 15, pp. 4337-4345, 2019.

[28] M. M. Lacerna, E. V. Bayogan, and L. B. Secretaria, "Rind color change and granulation in pummelo [Citrus maxima (Burm. ex Rumph.) Merr.] fruit as influenced by 1-methylcyclopropene," International Food Research Journal, vol. 25, no. 4, pp. 14831488, 2018.

[29] C. Bomal, F. Bedon, S. Caron et al., "Involvement of Pinus taeda MYB1 and MYB8 in phenylpropanoid metabolism and 
secondary cell wall biogenesis: a comparative in planta analysis," Journal of Experimental Botany, vol. 59, no. 14, pp. 3925-3939, 2008.

[30] T. Ookawa, K. Inoue, M. Matsuoka et al., "Increased lodging resistance in long-culm, low-lignin gh2 rice for improved feed and bioenergy production," Scientific Reports, vol. 4, p. 6567, 2014.

[31] Q. Niu, T. Wang, J. Li, Q. Yang, M. Qian, and Y. Teng, "Effects of exogenous application of GA4+7 and N-(2-chloro-4-pyridyl)- $\mathrm{N}^{\prime}$-phenylurea on induced parthenocarpy and fruit quality in Pyrus pyrifolia "Cuiguan"” Plant Growth Regulation, vol. 76, no. 3, pp. 251-258, 2015.

[32] R.-1. Sun, Q.-x. Zhou, and C.-x. Jin, "Cadmium accumulation in relation to organic acids in leaves of Solanum nigrum L. as a newly found cadmium hyperaccumulator," Plant and Soil, vol. 285, no. 1-2, pp. 125-134, 2006.

[33] M. Gao, J. L. Snider, H. Bai et al., "Drought effects on cotton (Gossypium hirsutum L.) fibre quality and fibre sucrose metabolism during the flowering and boll-formation period," Journal of Agronomy and Crop Science, vol. 206, no. 3, pp. 309-321, 2020.

[34] A. Ohyama, T. Nunome, and H. Fukuoka, "Effect of fruitspecific expression of the cell-wall-bound acid invertase gene Wiv-1 on hexose accumulation in tomato fruits," Bulletin of the National Institute of Vegetable and Tea Science, vol. 13, pp. 35-42, 2014.

[35] M. Ma, L. B. Wang, S. L. Zhang et al., "Acid vacuolar invertase 1 (PbrAc-Inv1) and invertase inhibitor 5 (PbrII5) were involved in sucrose hydrolysis during postharvest pear storage," Food Chemistry, vol. 320, p. 320, Article ID 126635, 2020.

[36] U. Rende, W. Wang, M. L. Gandla, L. J. Jönsson, and T. Niittylä, "Cytosolic invertase contributes to the supply of substrate for cellulose biosynthesis in developing wood," New Phytologist, vol. 214, no. 2, pp. 796-807, 2017.

[37] A. Mukhtar, A. A. Shahid, A. Sidra et al., "Sucrose synthase genes: a way forward for cotton fiber improvement," Biologia, vol. 73, no. 7, pp. 703-713, 2018.

[38] Y.-L. Ruan, "Rapid cell expansion and cellulose synthesis regulated by plasmodesmata and sugar: insights from the single-celled cotton fibre," Functional Plant Biology, vol. 34, no. 1, pp. 1-10, 2007.

[39] M. Ohtani, K. Morisaki, Y. Sawada et al., "Primary metabolism during biosynthesis of secondary wall polymers of protoxylem vessel elements," Plant Physiology, vol. 172, no. 3, pp. 1612-1624, 2016.

[40] Y. C. Huang, E. C. Hsiang, C. C. Yang, and A. Y. Wang, "New insight into the catalytic properties of rice sucrose synthase," Plant Molecular Biology, vol. 90, no. 1-2, pp. 127-135, 2016.

[41] M. Koubaa, J.-C. Cocuron, B. Thomasset, and A. P. Alonso, "Highlighting the tricarboxylic acid cycle: liquid and gas chromatography-mass spectrometry analyses of 13C-labeled organic acids," Analytical Biochemistry, vol. 436, no. 2, pp. 151-159, 2013.

[42] D. Seva Nayak and B. Singh, "Poly- $\beta$-hydroxybutyrate (PHB) biosynthesis, tricarboxylic acid activity and PHB content in chickpea (Cicer arietinum L.) root nodule," Russian Journal of Plant Physiology, vol. 64, no. 5, pp. 688-697, 2017.

[43] A. J. Mulholland and W. G. Richards, "Calculations on the substrates of citrate synthase I. Oxaloacetate," Journal of Molecular Structure: THEOCHEM, vol. 429, pp. 13-21, 1998.

[44] C. Y. Chen, X. Peng, J. Y. Chen, Z. Y. Gan, and C. P. Wan, "Mitigating effects of chitosan coating on postharvest senescence and energy depletion of harvested pummelo fruit response to granulation stress," Food Chemistry, vol. 348, Article ID 129113, 2021.

[45] Y. Luan, J. Cui, J. Li, N. Jiang, P. Liu, and J. Meng, "Effective enhancement of resistance to Phytophthora infestans by overexpression of miR172a and b in Solanum lycopersicum," Planta, vol. 247, no. 1, pp. 127-138, 2018.

[46] Y. T. Cai, H. Zhang, and Y. P. Qi, "Responses of reactive oxygen species and methylglyoxal metabolisms to magnesium-deficiency differ greatly among the roots, upper and lower leaves of Citrus sinensis," BMC Plant Biology, vol. 19, p. 76, 2019.

[47] J. Ma, Z. J. Cheng, J. Chen et al., "Phosphatidylserine synthase controls cell elongation especially in the uppermost internode in rice by regulation of exocytosis," PLoS One, vol. 11, no. 4, Article ID e0153119, 2016.

[48] L. Zhang, C. Gao, F. Mentink-Vigier et al., "Arabinosyl deacetylase modulates the arabinoxylan acetylation profile and secondary wall formation," The Plant Cell Online, vol. 31, no. 5, pp. 1113-1126, 2019.

[49] Y. Zhang, N. Nikolovski, M. Sorieul et al., "Golgi-localized STELLO proteins regulate the assembly and trafficking of cellulose synthase complexes in Arabidopsis," Nature Communications, vol. 7, Article ID 11656, 2016.

[50] T. Tsuyama, Y. Matsushita, K. Fukushima, K. Takabe, K. Yazaki, and I. Kamei, "Proton gradient-dependent transport of $p$-Glucocoumaryl alcohol in differentiating xylem of woody plants," Scientific Reports, vol. 9, p. 8900, 2019.

[51] P. Wang, X. Chen, C. Goldbeck, E. Chung, and B.-H. Kang, "A distinct class of vesicles derived from the trans -golgi mediates secretion of xylogalacturonan in the root border cell," The Plant Journal, vol. 92, no. 4, pp. 596-610, 2017.

[52] M. J. Meents, S. Motani, S. D. Mansfield, and A. L. Samuels, "Organization of xylan production in the golgi during secondary cell wall biosynthesis," Plant Physiology, vol. 181, no. 2, pp. 527-546, 2019.

[53] V. Kruft, H. Eubel, L. Jänsch, W. Werhahn, and H.-P. Braun, "Proteomic approach to identify novel mitochondrial proteins in Arabidopsis," Plant Physiology, vol. 127, no. 4, pp. 1694-1710, 2001.

[54] K. V. Padmalatha, D. P. Patil, K. Kumar et al., "Functional genomics of fuzzless-lintless mutant of Gossypium hirsutum L. cv. MCU5 reveal key genes and pathways involved in cotton fibre initiation and elongation," BMC Genomics, vol. 13, p. $624,2012$.

[55] A. Szarka, N. Horemans, S. Passarella et al., "Demonstration of an intramitochondrial invertase activity and the corresponding sugar transporters of the inner mitochondrial membrane in Jerusalem artichoke (Helianthus tuberosus L.) tubers," Planta, vol. 228, no. 5, pp. 765-775, 2008.

[56] M. L. Martín, L. Lechner, E. J. Zabaleta, and G. L. Salerno, “A mitochondrial alkaline/neutral invertase isoform (A/N-InvC) functions in developmental energy-demanding processes in Arabidopsis," Planta, vol. 237, no. 3, pp. 813-822, 2013.

[57] J. K. Burns, "Respiratory rates and glycosidase activities of juice vesicles associated with section-drying in citrus," HortScience, vol. 25, no. 5, pp. 544-546, 1990.

[58] J. A. O’Brien, A. Daudi, P. Finch et al., "A Peroxidase-dependent apoplastic oxidative burst in cultured Arabidopsis cells functions in MAMP-elicited defense," Plant Physiology, vol. 158, pp. 2013-2027, 2012.

[59] D. Jardim-Messeder, A. Caverzan, R. Rauber, E. S. Ferreira, M. Margis-Pinheiro, and A. Galina, "Succinate dehydrogenase (mitochondrial complex II) is a source of reactive oxygen 
species in plants and regulates development and stress responses,” New Phytologist, vol. 208, no. 3, pp. 776-789, 2015.

[60] B. Yin, J. Zhang, Y. Liu et al., "PtomtAPX, a mitochondrial ascorbate peroxidase, plays an important role in maintaining the redox balance of Populus tomentosa Carr," Scientific Reports, vol. 9, Article ID 19541, 2019.

[61] A. Shafi, T. Gill, I. Zahoor et al., "Ectopic expression of SOD and APX genes in Arabidopsis alters metabolic pools and genes related to secondary cell wall cellulose biosynthesis and improve salt tolerance," Molecular Biology Reports, vol. 46, pp. 1985-2002, 2019.

[62] S. B. Berman, F. J. Pineda, and J. M. Hardwick, "Mitochondrial fission and fusion dynamics: the long and short of it," Cell Death \& Differentiation, vol. 15, no. 7, pp. 1147-1152, 2008.

[63] F. F. Li, T. S. Munsey, and A. Sivaprasadarao, "TRPM2mediated rise in mitochondrial $\mathrm{Zn}^{2+}$ promotes palmitateinduced mitochondrial fission and pancreatic $\beta$-cell death in rodents," Cell Death \& Differentiation, vol. 24, pp. 1999-2012, 2017.

[64] D. G. Lee, J.-S. Min, H.-S. Lee, and D.-S. Lee, “Isoliquiritigenin attenuates glutamate-induced mitochondrial fission via calcineurin-mediated Drp1 dephosphorylation in HT22 hippocampal neuron cells," Neurotoxicology, vol. 68, pp. 133-141, 2018.

[65] Y. K. Zhang, R. J. Sun, X. L. Li, and W. H. Fang, "Porcine circovirus 2 induction of ROS is responsible for mitophagy in PK-15 cells via activation of Drp1 phosphorylation," Viruses, vol. 12, p. 289, 2020. 